by Engelmann and van Genderen Stort with regard to the retractility of the retinal cones of the frog's retina. We cannot in a brief notice do justice to this memoir, but we may give the following summary of one of the author's main conclusions. There are very remarkable structural and functional analogies between the retina and the integument; an external layer of pigment-cells is connected with a superficial layer of muscular fibres that contract in response to luminous stimuli. This initial local contraction constitutes a mechanical stimulus to subjacent nerve-cells, and is followed by a secondary total contraction of the longitudinal musculature of the siphon. Histologically the dermic element excitable by light is composed of: (1) pigmentcell, (2) contractile fibre, and (3) nerve-cell. Functionally the peripheral stimulus is a dermic phosphene analogous with a tactile phenomenon, viz., a mechanical excitation of the nervecell, by a movement of the contractile fibre, in consequence of a photo-chemical change in the pigment-cell.

\title{
A.D.W.
}

A Study of the Artefacts of the Neryous Sysem. By IrA VAN Gieson, M.D. (Reprinted from New York Medical Journal, September and October, 1892.)-Under this title Dr. Van Gieson gives a study of the "Topographical alteration of the grey and white matter of the spinal cord caused by autopsy bruises."

The word "artefact" has been ingeniously coined to avoid the use of the originally similar word, "artifice," which, owing to the common tendency of words to degenerate or take a less worthy meaning as language develops, would imply some disingenuousness on the part of the observer.

The author believes that "true heterotopia" of the grey matter may exist, but that it is extremely rare. He admits the existence of only six recorded cases, of which he gives a short resumé. In all these the displaced grey matter was apparently from the posterior horn and in the posterior columns. They were very minute and are presumed to be examples of true heterotopia because of the absence of any bruising of the surrounding white matter. We fail, however, to see in what respect these small displacements differ from the larger artificially produced alterations, except in degree. The grey matter must be supposed to be more diffluent than has hitherto been suspected, or the remarkable appearances produced artificially by Dr. Van Gieson would be impossible. We now come to the very interesting part of the work devoted to the description of the deformities produced by 


\section{ABSTRACTS OF BRITISH AND FOREIGN JOURNALS.}

bruising. A large number of drawings are given of sections from cords, first accidentally injured in removing, and secondly subjected after removal to every form of experimental injury. The effects produced are very remarkable, and the most prejudiced reader cannot fail to be struck by the close resemblance of the appearances to those in the recorded cases of so-called heterotopia. Even such effects as duplication of the cord have been produced artificially and figured by Dr. Van Gieson.

Then follows an analysis of the recorded cases of heterotopia, with reproductions of the plates, which Dr. Van Gieson condemns as artificial and not pathological at all.

The impression left on the mind of the reader is that there is no such thing as heterotopia, and the practical lesson to be learnt is, in removing a spinal cord never touch, bend, or twist it, and lift it only by its dura mater.

H. H. Tоотн.

Die Circulation im Gehirn und ihre Störungen. By Dr. Richard Geigel. Virchow's Archiv, vol. exix., p. 93.

Die Regulirung der Blutbewegung im Gehirn. By Dr. B. Lewy. Virchow's Archiv, vol. cxxii., p. 146.

"Experimentelle Beiträge zur Lehre yon der Blut-Circulation in der Schädel und Ruckgratshöhle." By Professor Hubert Grashey. J. F. Lehmann, München, 1892.

Geigel begins by pointing out that Althann, of Dorpat, writing in 1871, demonstrated that the condition of fulness of the brain vessels was no measure of the good or bad blood supply of the nervous elements; but that the point of importance is the ease with which oxygen is brought and carbonic acid removed from these elements.

This depends on two things:-

1. The chemical constitution of the blood.

2. The quantity of blood that passes through the capillaries in a given time.

Geigel proposes to designate a satisfactory flow of arterial blood through the capillaries as eudiæmorrhysis, too little as adiæmorrhysis-true anæmia cerebri, and too much as hyperdiæmorrbysis-true hyperæmia cerebri.

He then states a proposition as follows:-

Let $\mathrm{g}=$ the velocity of the circulation of the blood in the capillaries of the brain. This is directly proportional to the 